Review Article

\title{
Nanoparticle Therapy Is a Promising Approach in the Management and Prevention of Many Diseases: Does It Help in Curing Alzheimer Disease?
}

\author{
Lamyaa M. Kassem $\mathbb{D}^{1},{ }^{1}$ Nada A. Ibrahim, ${ }^{1}$ and S. Ayesha Farhana $\mathbb{D}^{2}$ \\ ${ }^{1}$ Department of Pharmacy Practice, Unaizah College of Pharmacy, Qassim University, P.O. Box: 5888, Unaizah 51911, \\ Qassim, Saudi Arabia \\ ${ }^{2}$ Department of Pharmaceutics, Unaizah College of Pharmacy, Qassim University, Unaizah, Qassim, Saudi Arabia
} P.O. Box: 5888

Correspondence should be addressed to Lamyaa M. Kassem; abdo.200312@yahoo.com

Received 20 September 2019; Accepted 6 June 2020; Published 7 August 2020

Guest Editor: Giorgio Vilardi

Copyright (c) 2020 Lamyaa M. Kassem et al. This is an open access article distributed under the Creative Commons Attribution License, which permits unrestricted use, distribution, and reproduction in any medium, provided the original work is properly cited.

\begin{abstract}
Treatment of brain diseases is always limited by the physiological nature of the highly selective blood-brain barrier (BBB) and the electrostatic charge of the nanoporous extracellular matrix. Nanomedical application provides a promising drug delivery revolution for the treatment of neurodegenerative diseases (NDDs). It depends on improving the pharmacokinetic distribution of drugs through the central nervous system. Nanotechnology offers various forms of nanoparticles, and these nanoparticles have brain-targeted and long-acting properties with minimal systemic adverse effects and motor complications. Gene delivery vehicles and nanocarriers including neurotrophic factors are promising therapeutics for many NDDs, and they can modulate neuronal survival and synaptic connectivity. Neurotrophic factors when integrated with the nanotechnological approaches can pass the BBB merely, representing a significant challenging track. Clinical trials proved that levodopa nanoparticles cause little motor complications which is a considerable drawback in treating Parkinson's disease with levodopa. Recently, nanotechnology had patented new formulations and achieved various advanced procedures for management, and even prevention, of NDDs. Nanotechnology can be integrated into neuroscience to fight against neurodegenerative diseases. Primary research studies in using nanoparticles to cure Alzheimer disease (AD) are promising but are still in need for more investigations. The present paper aims to review, outline, and summarize various efforts done in the field of using nanoparticles in the management of Alzheimer.
\end{abstract}

\section{Introduction to Neurodegenerative Diseases and Nanoparticles}

Neurodegenerative diseases (NDDs) are debilitating disorders that primarily affect the neuron cells, and they degenerate the brain and central nervous system (CNS) progressively which severely disturb the motor and cognitive functions which may end with either complete disabilities or death. Symptoms of NDDs often progress slowly over the years [1]. The resulting short- or long-term impairments and limitations may burden the quality of life of patients, families, and social networks [2]. NDDs are of different types such as Alzheimer's disease (AD),
Parkinson's disease (PD), dementia, motor neuron diseases (MND), Huntington's disease (HD), prion disease, and schizophrenia. In this review, we will focus on challenging experimental and clinical trials in the treatment of the $\mathrm{AD}$ as one of the most common NDDs among elders. Despite the variations in clinical characteristics, there are some molecular and subcellular similarities between these NDDs. NDDs have standard features which include a late appearance in life, synaptic abnormalities, extensive neuronal loss, and gathering and collection of protein within the brain [3]. Millions of people globally may have dementia mainly due to $\mathrm{AD}$, which causes an irreversible type. It occurs in nearly $1 \%$ of the individuals in the age of 
more than 50 yrs and may jump to $50 \%$ in adults more than 70 yrs [4]. Profoundly, these percentages are expected to increase with the worldwide increase in the population mean age. $\mathrm{AD}$ is a chronic NDD, and it is considered as a leading cause of dementia in elders; the causative mechanisms of the $\mathrm{AD}$ are still unclear. The amyloid beta peptide protein plaques are deposited extracellularly around the walls of cerebral vessels and in the brain parenchyma [5]. They degenerate a person's physical and mental skills during their prime working years and has no cure [6]. In this review, we aim to review, outline, and summarize various efforts done in the field of using nanoparticles in the management of Alzheimer.

Various fields of sciences were interested in using this era of nanotechnology in challenges in the treatment and diagnosis of NDDs, see Figure 1 which reflects 236 published papers since 1994 of different fields of science with years of citations as provided by the Web of Science search result analysis [7].

The BBB has a nature of specific permeability which represents the main challenge in the treatment of NDDs. The challenge is either to manipulate the drug in a ridiculously small size that can easily pass the cells of the BBB or to change the physicochemical parameters of the drug in a way that it will be lipid soluble. All the available CNS treatment medications can hardly penetrate the BBB to give the required therapeutic effect in the brain and CNS. Considerable research studies indicate that enhancing the permeability and bioavailability of the BBB is needed to improve therapeutic outcomes. Nanotechnology medical applications offer many new promising opportunities for efficient brain drug delivery across the BBB that we will outline throughout the review [8].

Nanoparticle systems can be used with several routes of administration such as oral [9], nasal [10], and parenteral including intravenous [11], intramuscular [12], subcutaneous [13], and intraocular [14]. The majority of the nanoparticle systems that are used are composed of both natural and synthetic polymers, proteins, and polysaccharides in which the drug is incorporated for targeted brain delivery [15]. These polymeric nanoparticles have promising brain-targeting characters as modifiable chemical characters for cell-specific and selective targeting purposes and the ability to change the drug-releasing pattern for controlled, sustained, or extended drug effects, shielding the in situ drug in a way that interferes with the lipophilic requirement to pass the $\mathrm{BBB}$, which can also protect the drug from the enzymatic degradation or the first-pass metabolism effects, which all can help to increase the bioavailability, decrease the required therapeutic dose, and hence decrease the drug toxicity and systemic adverse effects. The size of the nanoparticle systems ranges from 1 to $1000 \mathrm{~nm}$. There are many forms of nanosystems such as nanoparticles, nanocapsules, nanospheres, nanogels, nanosuspensions, nanomicelles, and nanoliposomes. The choice of a proper type of nanosystem depends on the nature of the targeted cell or location, the nature and mass of the drug, the required pattern of drug release, type of the dosage form, and, in general, the nature of the drug challenge to reach the brain or CNS [16].

\section{Advantages of Using Nanoparticles for CNS- Targeted Drug Delivery}

In general, nanoparticles offer many promising advantages to be applied in the medical fields for preparation of new advanced dosage forms: high drug-loading capacity which lowers the possibilities of chemical interactions or toxicity, high surface area-to-volume ratio, ease of manipulation for parenteral administration due to particle size and surface characteristics of nanoparticles, capability to use for active and passive drug-targeting strategies, sustained and controlled release purposes of drug production, and site-specific targeting by magnetic guidance or by attaching targeting ligands to the surface of particles [17]. There are many factors which affect the method of selection for the nanoparticle manufacturing materials such as required nanoparticle size, targeting properties, lipid or water solubility and their respected hydrophobicity or hydrophilicity, chemical and physical stability, surface charge and permeability, biodegradability, biocompatibility, cytotoxicity, drug release profile, and antigenicity of the final product [18].

Blood-brain barriers challenge the drug delivery design. In general, pharmaceutical drug dosage forms cannot easily cross the BBB; however, they can pass only by active efflux or carriermediated transport in the usual drug formulations with very little bioavailability $[19,20]$. In vivo and in vitro studies verified the passage of nanoparticles through the BBB. They supported the incorporation of the nanotherapeutic substances into the brain, so nanoparticles can also be applied in diagnosis as well as brain-targeted therapy and gene therapy [21-23].

Ideal nanoparticles properties for brain drug delivery purposes:

(1) Nanoparticles must be nontoxic, biodegradable, and biocompatible, e.g., polylactide homopolymers and polylactide-co-glycolide polymer nanoparticles [24].

(2) Nanoparticle size is preferred to be lower than $100 \mathrm{~nm}$ where the rate of clearance increases with increasing particle size more than $100 \mathrm{~nm}$, so it affects both the biodistribution and bioavailability [25].

(3) Physical stability and preventing aggregation in the blood is necessary, where several types of nanoparticles were considered to be toxic due to physical rather than chemical surface properties [26].

(4) Prolonged blood circulation time, in which only PEGylated nanoparticles had lower uptake and prolonged time [27].

(5) Targeted brain delivery with no need for active reflux or carrier-mediated pathway, so as to enhance drug bioavailability and efficacy and reduce the required therapeutic dose and its resultant efficacy.

(6) Noninvasive gene-targeting brain delivery, e.g., PEGylated immunoliposomes via receptor-mediated transcytosis which enter their content into the brain tissues without injuring the BBB [28].

(7) Cost-effective studies should evaluate the potential usage of nanomedicine for clinical purposes. 


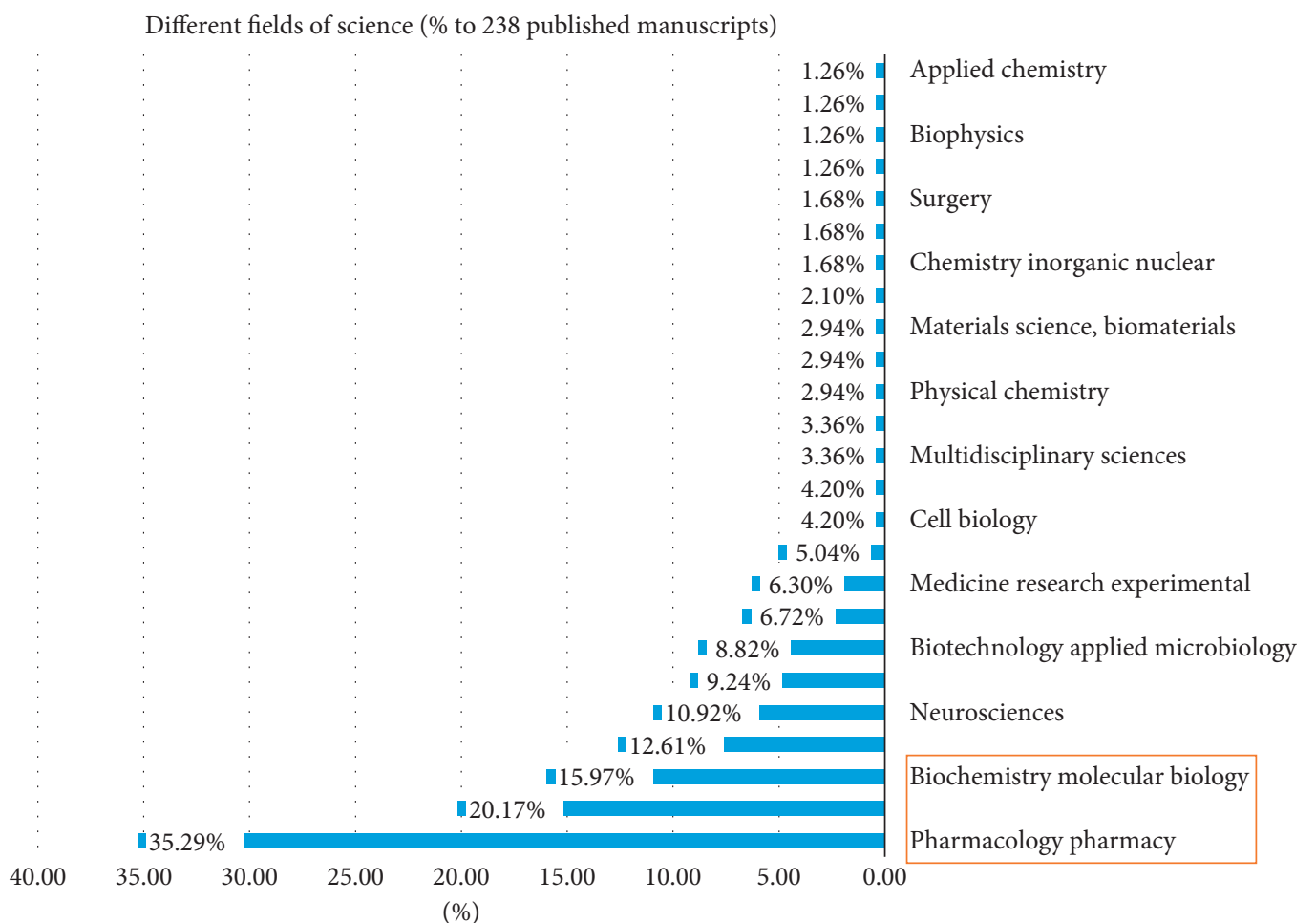

FIGURE 1: Different fields of science interested in using nanotechnology for the management of NDDs.

Increasing treatment cost will limit the number of patients who can benefit from those medications [29].

\section{Experimental Applications of Nanoparticles in Treatment of Neurodegenerative Diseases}

3.1. Therapeutic Challenges. Recent application of nanotechnology in biomedicine and the optimistic growing of researchers and applications in the fields of nanomedicine and neuroscience provide the scientists with a promising hope for the investigation and management of NDDs. The applications include targeted drug delivery, diagnostic services, and manufacturing of advanced biocompatible substances [30, 31]. Solid nanoparticles are novel potential colloidal carrier systems and matrix-like units prepared by polymers or lipids; they are administered parenterally by the intravenous route. This technology manipulates nanometerscaled $(1-100 \mathrm{~nm})$ bioengineered materials with functional groups that can interact at the molecular level with biological systems [32]. Understanding these bioengineered nanoparticles is a vital key to recognize various nanomedical applications. The unique features of nanoparticles lie behind their attractiveness for medical purposes. The features are a very high surface area of the nanoparticles to the mass ratio and the ability to be functioning at their surface, so they can adsorb or carry other substances such as medicines, diagnostic, or therapeutic probes and proteins. Nanoparticles can be prepared with specific quantum properties which are promising in diagnostic and imaging purposes [33].
Figure 2 illustrates different types of nanoparticles with their average nanosize that can be injected intracerebrally to treat Alzheimer disease.

\section{Recent Applications of Nanoparticles in the Management of Neurodegenerative Diseases (NDDs)}

Peptide-polymer conjugates profoundly improved bioavailability and brain delivery of drugs. They advance pharmacokinetics by raising their molecular mass, so they shield themselves from proteolytic enzymes. These novel approaches created new opportunities for the future development of neurotherapeutic drugs and offer great hope for the treatment of brain diseases [34, 35]. Despite the clinical potentiality of the peptides, native peptides have been seen with limited pharmacokinetics. They have low bioavailability and metabolic stability in normal physiological conditions [36]. Several interventions aimed to enhance biological features of peptides for clinical applications by inclusion of synthetic amino acids, pseudopeptide bonding, cyclization, and chemical modification by conjugation to polymers such as in different nanoparticle systems offer great hope in the treatment of brain dysfunctions [37].

THPdb (http://crdd.osdd.net/raghava/thpdb/) a database of the Food and Drug Administration (FDA) contains therapeutically approved peptides and proteins in which the data from 985 manuscripts and 70 patents were compiled. The latest version of the THPdb database includes full information on 239 US FDA-approved 


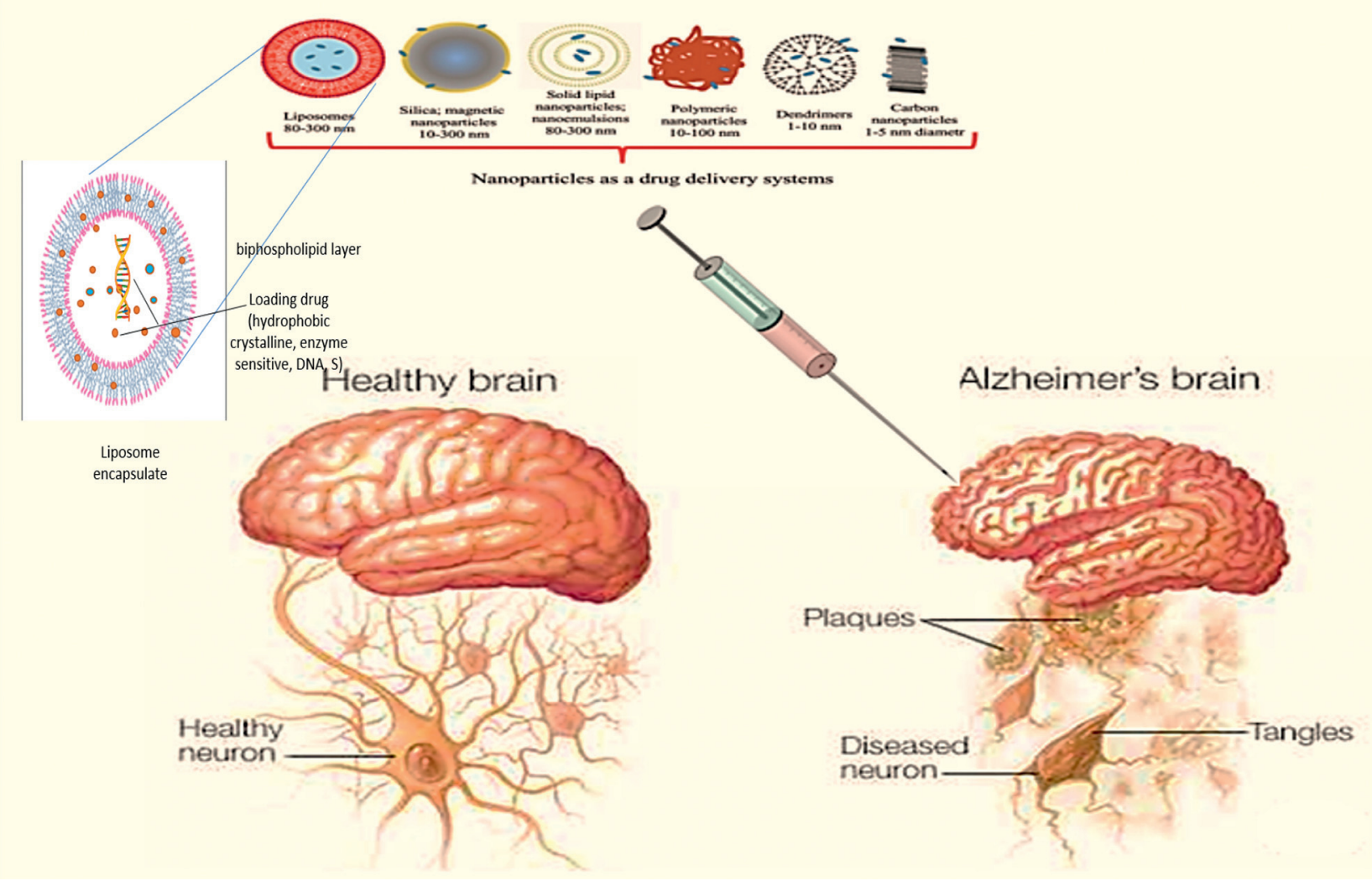

FIGURE 2: Diagrammatic ICV injection for different forms of drug-loaded nanosystems.

therapeutic peptides and proteins and their 380 drug derivatives [38]. The latest nanocarrier system was designed by Yemisci et al., where chitosan nanoparticles were used as a carrier for small peptides such as caspase inhibitor Z-DEVD-FMK or the large peptide-like fibroblast growth factor through the BBB. These nanoparticles are selectively targeting the brain without passing the liver and spleen [39]. The route of nanoparticle administration reveals essential attention to defeat the physiological BBB and to achieve therapeutic drug concentrations therein. Therefore, alternative routes of administration for brain drug delivery are being developed, such as the intravenous and oral route, inhalation or intratracheal, and intrathecal drug delivery systems [40]. There is a growing interest in developing targeted brain delivery medicines and polymeric or lipid nanoparticles, which have a high degree of specificity, to neurorepair and protection. The main aim in the design of a drug delivery nanosystem is to protect therapeutic agents and increase their biodistribution and therapeutic index to the brain [41]. These nanosystems such as nanoparticles including nanospheres and nanocapsules, micelles, dendrimers, nanocrystals, and nanogolds mainly contain polymer- or lipid-based carriers. Nanoparticles represent a promising strategy in which the polymeric and biocompatible devices could deliver immunoprotected therapeutic compounds to the brain [42].

\section{Advances of Nanoparticles in the Management of Alzheimer Disease (AD)}

Alzheimer's disease (AD) is a progressive neurodegenerative disease that is manifested by deterioration of cognitive, neuropsychiatric, and behavioral motor functions. Accumulation of beta amyloid aggregates is the hallmark of $\mathrm{AD}$ which are neurotoxic, and the resultant oxidative stress causes damage to neurons and brain cells. The main aim of $\mathrm{AD}$ therapy is to protect neurons against the oxidative stress, antiamyloid therapy, degeneration, and to pass through the $\mathrm{BBB}$ for brain-targeted action [43]. In vitro and in vivo studies for managing AD were done by Liu et al. in 2016 using a mice model; they successfully achieved therapeutic brain delivery by parenteral injection of a multifunctional nanoparticle. This multifunctional nanosystem used PEGylated dendrigraft poly-l-lysine as a carrier of the therapeutic gene and the peptide [44]. Cranial implants of microencapsulated vascular endothelial growth factor(VEGF-) secreting cells elevated brain vessel formation in the cerebral cortex corresponding to the control group. Findings of this study proved the earlier fact that considers VEGF has a potential therapeutic effect on brain disorders such as angiogenesis, protection of neurons, and cerebral microvascular exchange of nutrients $[45,46]$. Direct injection of bolus doses of drug nanoparticles into the brain has many advantages: high concentration in the brain was 
TABLE 1: Drugs used for investigating the effective therapy of different nanoparticles in the treatment of Alzheimer.

\begin{tabular}{|c|c|c|c|c|c|c|c|}
\hline Drug & Composite & $\begin{array}{c}\text { Type of } \\
\text { nanoparticles }\end{array}$ & Model & Improved properties & $\begin{array}{l}\text { Shape and } \\
\text { particle size }\end{array}$ & $\begin{array}{c}\text { Zeta } \\
\text { potential }\end{array}$ & References \\
\hline $\begin{array}{l}\text { Pd hydride } \\
(\mathrm{PdH})\end{array}$ & $\begin{array}{l}\text { Pd hydride } \\
\quad(\mathrm{PdH})\end{array}$ & Nanoparticles & Mice & $\begin{array}{l}\text { In situ and sustained } \\
\text { release of high payload } \\
\text { of hydrogen, decreasing } \\
\text { the oxidative stress }\end{array}$ & $\begin{array}{l}\text { Cubic shape with } \\
\text { uniform size } \\
\text { (about } 30 \mathrm{~nm} \text { ) }\end{array}$ & NA & {$[61]$} \\
\hline $\begin{array}{l}\text { Vitamin D- } \\
\text { binding } \\
\text { protein } \\
(\mathrm{DBP}) \\
\end{array}$ & DBP-PLGA & Nanoparticles & $\begin{array}{l}\mathrm{A} \beta- \\
\text { overexpressing } \\
\text { (5XFAD) mice }\end{array}$ & $\begin{array}{c}\text { Decrease } \mathrm{A} \beta \text { aggregation } \\
\text { and accumulation }\end{array}$ & $\begin{array}{l}\text { Spherical and } \\
\text { uniform size, } \\
\text { average } \\
226.6 \pm 44.4 \mathrm{~nm} \\
\end{array}$ & $-0.144 \mathrm{mV}$ & {$[62]$} \\
\hline $\begin{array}{l}\text { Curcumin } \\
(\mathrm{Cu}) \text { and } \\
\text { selenium } \\
(\mathrm{Se})\end{array}$ & Se-Cur/PLGA & Nanospheres & $\begin{array}{l}\text { Transgenic mice } \\
\text { (5XFAD) }\end{array}$ & Decreases the amyloid- $\beta$ & $\begin{array}{l}\text { Spherical and } \\
\text { uniform size, } \\
\text { average } \\
70.5 \pm 6 \mathrm{~nm}\end{array}$ & NA & {$[63]$} \\
\hline SNPs & $\begin{array}{c}\text { Aqueous } \\
\text { extraction of } \\
\text { Lampranthus } \\
\text { coccineus, } \\
\text { Malephora lutea, } \\
\text { F. Aizoaceae } \\
\end{array}$ & Nanoparticles & $\begin{array}{c}\text { Adult male } \\
\text { albino rats of } \\
\text { Sprague Dawley }\end{array}$ & $\begin{array}{l}\text { Anticholinesterase and } \\
\text { antioxidant activity }\end{array}$ & $\begin{array}{c}\text { Spherical } \\
\text { nanoparticles } \\
\text { with a mean size } \\
\text { from } 12.86 \mathrm{~nm} \text { to } \\
28.19 \mathrm{~nm}\end{array}$ & NA & {$[64]$} \\
\hline $\begin{array}{l}\mathrm{A} \beta 1-42 \\
\text { peptide }\end{array}$ & $\begin{array}{c}\mathrm{A} \beta_{1-42} \text { peptide } \\
\text { monoclonal } \\
\text { antibody to } \mathrm{PEG} \\
\text { chain (anti-a } \beta 1- \\
42-\mathrm{NPs} \text { ) }\end{array}$ & $\begin{array}{c}\text { PEGylated } \\
\text { nanoparticles }\end{array}$ & $\begin{array}{l}\text { AD-like } \\
\text { transgenic mice }\end{array}$ & $\begin{array}{l}\text { Promote } \mathrm{A} \beta_{1-42} \\
\text { elimination through the } \\
\text { "sink effect" }\end{array}$ & $125 \mathrm{~nm}$ & $\begin{array}{l}-20 \text { to } \\
-30 \mathrm{mV}\end{array}$ & {$[65]$} \\
\hline Zinc & Zinc-PLGA & Nanoparticles & $\begin{array}{l}\text { Wild-type (WT) } \\
\text { and APP23 mice }\end{array}$ & $\begin{array}{c}\text { Reduction in plaque size } \\
\text { and affects the release of } \\
\text { proinflammatory } \\
\text { cytokines IL- } 6 \text { and IL-18 }\end{array}$ & $200-220 \mathrm{~nm}$ & NA & {$[66]$} \\
\hline Coumarin & TQNP/H102 & Nanoparticles & $\begin{array}{c}\mathrm{APP} / \mathrm{PS} 1 \\
\text { transgenic mice }\end{array}$ & $\begin{array}{l}\text { Decreasing amyloid } \\
\text { plaques, increasing } A \beta \text { - } \\
\text { degrading enzymes, } \\
\text { reducing tau protein } \\
\text { phosphorylation, } \\
\text { protecting synapses, and } \\
\text { improving the spatial } \\
\text { learning and memory }\end{array}$ & $\begin{array}{l}100 \mathrm{~nm} \text { that may } \\
\text { increase on } \\
\text { loading with } \\
\text { H102 peptide }\end{array}$ & $-25 \mathrm{mV}$ & {$[67]$} \\
\hline
\end{tabular}

DBP-PLGA: vitamin D-binding protein loaded PLGA (poly (D,L-lactic acid-co-glycolic acid)); Se: selenium; A $\beta$ : amyloid beta protein; TQNP is a multifunctionalized nanoparticle system based on poly(ethylene glycol)-poly(lactic acid) (PEG-PLA) and modified with TGN peptides as the brain ligand and QSH peptides for A42-binding (TQNP) [61], to target amyloid plaques in the brain; TGN (TGNYKALHPHNGC), QSH (QSHYRHISPAQVC), H102 peptide (HKQLPFFEED), and A $\beta 42$ were peptides; NA: not available; SNPs: silver nanoparticles.

achieved with no alteration or impairment in BBB functions, enhancement of vascularity at the cerebral cortex, and diminishing of the amyloid beta deposits [47]. Based on this fact, the therapeutic use of VEGF microencapsulation was patented $[48,49]$. Parenteral administration of medications ensures the delivering of therapeutic medicines with proper doses to the cerebrospinal compartments, but it exposes the ependymal surface to a higher level of drugs that may cause toxic rather than therapeutic effects. Treatment with growth factor nanoreleasing systems is highly promising for NDDs, but it may cause severe side effects in the brain due to the direct injection to the brain. Axonal sprouting and Schwann cell hyperplasia were reported after the intracerebroventricular (ICV) injection of the nerve growth factor [50]. Periventricular astrogliosis is also reported due to the ICV injection of the fibroblast growth factor [51].
Another design of physiologically active nanoparticles is the cytokine-derived peptide nanopeptide that is used in the preparation of drug dosage forms for the management of NDDs, in precise, AD [52]. They can be administered by parenteral, topical, oral prelingual, rectal, or intraocular routes, but the preferred routes are subcutaneous, intranasal, intraperitoneal (IV), and intravenous routes (IP). Topical preparations such as patch, pomade, or gel are available [53]. Experimental studies proved that the PAT nanopeptide exhibits some biological activity when it is administered by the ICV route-which bypasses the BBB-and by the parenteral route (intraperitoneal). This latter mode of administration highlights the fact that that the product crosses the $\mathrm{BBB}$ and reaches the brain. To pass the $\mathrm{BBB}$, persons skilled in the art know that the molecular and physicochemical properties of the molecule must fulfil the rule-of-five criteria described by Lipinski et al. (a low molecular weight, its 
lipophilicity, its charge, etc.). However, it was a surprise to notice that the PAT peptide, which does not fulfil all these criteria, crosses the BBB [54].

Monoclonal antibodies have been anticipated as useful options for both in vivo diagnosis and treatment. Recent clinical trials have assumed that this promising potential impact is becoming a reality. Attention of researchers is moving towards the production of sufficient quantity of monoclonal antibodies with high purity and quality for widespread human use. Microencapsulation technique is currently used for large-scale production of both human and murine types of monoclonal antibodies for in vivo applications [55]. Encapsulated antibodies are now used for the treatment of brain diseases. Microencapsulation used for controlled drug delivery of anti-VE-cadherin monoclonal antibodies can be considered as a new therapeutic option for the inhibition of angiogenesis [56]. Nanoparticle encapsulation of the drug maintains about $80 \%$ of its enzymatic activity with no cytotoxicity at the level of therapeutic concentration [57].

A novel product of siRNA nanoparticles used the peptide-tagged polyethylene glycol- (PEG-) related chitosan polymer as a drug delivery system for NDD applications. It is used to deliver a functional siRNA against the Ataxin-1 gene in an in vitro simulation of NDD. The results indicate that the SCA1 protein was successfully suppressed after $48 \mathrm{hr}$ of transfection. The result of this study has great impact on NDD like AD, PD, and others [58]. Cerium oxide nanoparticles (CeONPs) have recently appeared as a new therapeutic option which extends the therapeutic impact of using nanomedicine in the treatment of NDD such as the $\mathrm{AD}, \mathrm{PD}$, multiple sclerosis, ischemic stroke, and amyotrophic lateral sclerosis. Their average nanosize helps the smooth passage through the BBB. However, its antioxidant activity can change the signaling pathway, which enables the scavenging of reactive oxygen radicals [59]. Novel galantamine-loaded polymeric nanoparticles are another recently emerged drug delivery systempp for treating neurodegenerative diseases. Galantamine-loaded polymeric nanoparticles (GNPs) were prepared by the nanoemulsion templating technique, and GNPs have safe, biocompatible, and biodegradable properties which make them suitable for the intravenous use [57]. Silica nanoparticles (SiNPs) are widely used as a drug delivery carrier and also used in molecular detection and cellular manipulations, and many research studies try to apply them in the nanoneuro-medical applications. However, SiNPs may dangerously affect the brain by causing neurotoxicity, inflammation, and degeneration by its amyloidogenesis action, which is a hallmark of Alzheimer's disease [60].

Table 1 summarizes some recent pharmacological studies that investigate the effective therapy of different nanoparticles in the treatment of Alzheimer.

\section{Conclusion}

Targeted nanoparticle brain drug delivery aims to improve the clinical outcomes with developing the diagnostics and therapeutic efficacy of medication in managing Alzheimer disease. Many efforts on this approach were done and are still ongoing for effective symptomatic therapy, suspending the progression of different types of neurodegenerative diseases and decreasing the well-known severe complications of therapeutic medication. Some nanopharmaceuticals are patented in treating NDDs in animals, some still in the experimental stage, and some proved to be safe, while others reported cytotoxicity. Identification of putative gene-targeted therapy using compacted DNA and RNA plasmids using viral or nonviral vector technique research studies are also still going on, and all these studies are promising for managing and may preventing NDDs, but until now there is no evidence for the efficacy and safety margin of using nanoparticles in patients with AD.

\section{Conflicts of Interest}

The authors of this paper have no conflicts of interest that influence the results or interpretation of reviewed manuscripts.

\section{References}

[1] B. L. Rajak, M. Gupta, and D. Bhatia, "Growth and advancements in neural control of limb," Biomedical Science and Engineering, vol. 3, no. 3, pp. 46-64, 2015.

[2] S. S. Dikmen, J. E. Machamer, J. M. Powell, and N. R. Temkin, "Outcome 3 to 5 years after moderate to severe traumatic brain injury 11 No commercial party having a direct financial interest in the results of the research supporting this article has or will confer a benefit upon the author(s) or upon any organization with which the author(s) is/are associated," Archives of Physical Medicine and Rehabilitation, vol. 84, no. 10, pp. 1449-1457, 2003.

[3] Y. Choonara, V. Pillay, L. Du Toit et al., "Trends in the molecular pathogenesis and clinical therapeutics of common neurodegenerative disorders," International Journal of Molecular Sciences, vol. 10, no. 6, pp. 2510-2557, 2009.

[4] L. Bertram and R. E. Tanzi, "The genetic epidemiology of neurodegenerative disease," Journal of Clinical Investigation, vol. 115, no. 6, pp. 1449-1457, 2005.

[5] A. W. J. Morris, M. M. Sharp, N. J. Albargothy et al., "Vascular basement membranes as pathways for the passage of fluid into and out of the brain," Acta Neuropathologica, vol. 131, no. 5, pp. 725-736, 2016.

[6] P. Dayalu and R. L. Albin, "Huntington disease," Neurologic Clinics, vol. 33, no. 1, pp. 101-114, 2015.

[7] Web of Science, "Nanotechnology neurodegenerative diseases," Results Analysis, 2020, https://wcs-webofknowledgecom.sdl.idm.oclc.org/RA/analyze.do?product=WOS\&SID=E 39jrRpJaOJawVLdYQc\&field=TASCA_JCRCategories_JCR Categories_en\&yearSort=false.

[8] C. Saraiva, C. Praça, R. Ferreira, T. Santos, L. Ferreira, and L. Bernardino, "Nanoparticle-mediated brain drug delivery: overcoming blood-brain barrier to treat neurodegenerative diseases," Journal of Controlled Release, vol. 235, pp. 34-47, 2016.

[9] Z. Izadi, A. Divsalar, A. A. Saboury, and L. Sawyer, “ $\beta$-lactoglobulin-pectin nanoparticle-based oral drug delivery system for potential treatment of colon cancer," Chemical Biology \& Drug Design, vol. 88, no. 2, pp. 209-216, 2016. 
[10] L. Casettari and L. Illum, "Chitosan in nasal delivery systems for therapeutic drugs," Journal of Controlled Release, vol. 190, pp. 189-200, 2014.

[11] J. Kreuter, "Drug delivery to the central nervous system by polymeric nanoparticles: what do we know?" Advanced Drug Delivery Reviews, vol. 71, pp. 2-14, 2014.

[12] K. Nakano, J.-I. Koga, and K. Egashira, "Nanoparticle-mediated endothelial cell-selective drug delivery system," in Therapeutic Angiogenesis, pp. 247-266, Springer, Berlin, Germany, 2017.

[13] J. Zhou, T. R. Patel, J. M. Piepmeier, and W. M. Saltzman, "Highly penetrative nanocarriers for treatment of CNS disease," US 20150118311A1, 2020.

[14] A. Vashist, A. Kaushik, A. Vashist et al., "Nanogels as potential drug nanocarriers for CNS drug delivery," Drug Discovery Today, vol. 23, no. 7, pp. 1436-1443, 2018.

[15] N. Rajput, "Methods of preparation of nanoparticles-a review," International Journal of Advances in Engineering \& Technology, vol. 7, no. 6, p. 1806, 2015.

[16] G. Modi, V. Pillay, and Y. E. Choonara, "Advances in the treatment of neurodegenerative disorders employing nanotechnology," Annals of the New York Academy of Sciences, vol. 1184, no. 1, pp. 154-172, 2010.

[17] G. Tiwari, R. Tiwari, S. Bannerjee et al., "Drug delivery systems: an updated review," International Journal of Pharmaceutical Investigation, vol. 2, no. 1, p. 2, 2012.

[18] K. G. Budinski and M. K. Budinski, Engineering Materials, Pearson Education India, Bengaluru, India, 1949.

[19] L. Battaglia, P. P. Panciani, E. Muntoni et al., "Lipid nanoparticles for intranasal administration: application to nose-tobrain delivery," Expert Opinion on Drug Delivery, vol. 15, no. 4, pp. 369-378, 2018.

[20] C. A. Peptu, L. Ochiuz, L. Alupei, C. Peptu, and M. Popa, "Carbohydrate based nanoparticles for drug delivery across biological barriers," Journal of Biomedical Nanotechnology, vol. 10, no. 9, pp. 2107-2148, 2014.

[21] T.-T. Zhang, W. Li, G. Meng, P. Wang, and W. Liao, "Strategies for transporting nanoparticles across the bloodbrain barrier," Biomaterials Science, vol. 4, no. 2, pp. 219-229, 2016.

[22] R. Bayford, T. Rademacher, I. Roitt, and S. X. Wang, "Emerging applications of nanotechnology for diagnosis and therapy of disease: a review," Physiological Measurement, vol. 38, no. 8, pp. R183-R203, 2017.

[23] O. Betzer, M. Shilo, R. Opochinsky et al., "The effect of nanoparticle size on the ability to cross the blood-brain barrier: an in vivo study," Nanomedicine, vol. 12, no. 13, pp. 1533-1546, 2017.

[24] F. Masood, "Polymeric nanoparticles for targeted drug delivery system for cancer therapy," Materials Science and Engineering: C, vol. 60, pp. 569-578, 2016.

[25] N. Hoshyar, S. Gray, H. Han, and G. Bao, "The effect of nanoparticle size on in vivo pharmacokinetics and cellular interaction," Nanomedicine, vol. 11, no. 6, pp. 673-692, 2016.

[26] A. Gnach, T. Lipinski, A. Bednarkiewicz, J. Rybka, and J. A. Capobianco, "Upconverting nanoparticles: assessing the toxicity," Chemical Society Reviews, vol. 44, no. 6, pp. 1561-1584, 2015.

[27] H. Ou, T. Cheng, Y. Zhang et al., "Surface-adaptive zwitterionic nanoparticles for prolonged blood circulation time and enhanced cellular uptake in tumor cells," Acta Biomaterialia, vol. 65, pp. 339-348, 2018.

[28] A. V. Kabanov and E. V. Batrakova, "Polymer nanomaterials for drug delivery across the blood brain barrier," in
Neuroimmune Pharmacology, pp. 847-868, Springer, Berlin, Germany, 2017.

[29] D. M. Parikh, Handbook of Pharmaceutical Granulation Technology, CRC Press, Boca Raton, FL, USA, 2016.

[30] S. B. Pehlivan, "Nanotechnology-based drug delivery systems for targeting, imaging and diagnosis of neurodegenerative diseases," Pharmaceutical Research, vol. 30, no. 10, pp. 2499-2511, 2013.

[31] O. Lupan, "Nanotechnology and its applications in medicine," in Health Technology Management, Institutional Repository of the Technical University of Moldova (IRTUM), Chişinău, Moldova, 2016.

[32] V. J. Pansare, Fundamental and Applied Studies in Nanoparticle Biomedical Imaging, Stabilization, and Processing, Princeton University, Princeton, NJ, USA, 2015.

[33] L. A. Lane, X. Qian, and S. Nie, "SERS nanoparticles in medicine: from label-free detection to spectroscopic tagging," Chemical Reviews, vol. 115, no. 19, pp. 10489-10529, 2015.

[34] J. Ren, R. Zhang, and J. M. Regenstein, "Adding biological function to nonbiological nanoparticles," in Nutrient Delivery, pp. 497-534, Elsevier, Amsterdam, Netherlands, 2017.

[35] W. Chen, C. Zhan, B. Gu et al., "Targeted brain delivery of itraconazole via RVG29 anchored nanoparticles," Journal of Drug Targeting, vol. 19, no. 3, pp. 228-234, 2011.

[36] F. Antunes, F. Andrade, D. Ferreira, H. Morck Nielsen, and B. Sarmento, "Models to predict intestinal absorption of therapeutic peptides and proteins," Current Drug Metabolism, vol. 14, no. 1, pp. 4-20, 2013.

[37] L. Gentilucci, R. De Marco, and L. Cerisoli, "Chemical modifications designed to improve peptide stability: incorporation of non-natural amino acids, pseudo-peptide bonds, and cyclization," Current Pharmaceutical Design, vol. 16, no. 28, pp. 3185-3203, 2010.

[38] S. S. Usmani, G. Bedi, J. S. Samuel et al., "THPdb: database of FDA-approved peptide and protein therapeutics," PloS One, vol. 12, no. 7, 2017.

[39] M. Yemisci, S. Caban, Y. Gursoy-Ozdemir et al., "Systemically administered brain-targeted nanoparticles transport peptides across the blood-brain barrier and provide neuroprotection," Journal of Cerebral Blood Flow \& Metabolism, vol. 35, no. 3, pp. 469-475, 2015.

[40] C. V. Pardeshi and V. S. Belgamwar, "Direct nose to brain drug deliveryviaintegrated nerve pathways bypassing the blood-brain barrier: an excellent platform for brain targeting," Expert Opinion on Drug Delivery, vol. 10, no. 7, pp. 957-972, 2013.

[41] G. Tosi, B. Bortot, B. Ruozi et al., "Potential use of polymeric nanoparticles for drug delivery across the blood-brain barrier," Current Medicinal Chemistry, vol. 20, no. 17, pp. 2212-2225, 2013.

[42] S. C. Tang, Impact of Apical ABC Transporters on Pharmacokinetics of Targeted Anticancer Drugs, Utrecht University, Utrecht, Netherlands, 2013.

[43] A. Nazem and G. A. Mansoori, "Nanotechnology solutions for Alzheimer's disease: advances in research tools, diagnostic methods and therapeutic agents," Journal of Alzheimer's Disease, vol. 13, no. 2, pp. 199-223, 2008.

[44] Y. Liu, S. An, J. Li et al., "Brain-targeted co-delivery of therapeutic gene and peptide by multifunctional nanoparticles in Alzheimer's disease mice," Biomaterials, vol. 80, pp. 33-45, 2016.

[45] A. Larpthaveesarp, D. Ferriero, and F. Gonzalez, "Growth factors for the treatment of ischemic brain injury (growth 
factor treatment)," Brain Sciences, vol. 5, no. 2, pp. 165-177, 2015.

[46] E. Herrán, R. Pérez-González, M. Igartua, J. L. Pedraz, E. Carro, and R. M. Hernández, "VEGF-releasing biodegradable nanospheres administered by craniotomy: a novel therapeutic approach in the APP/Ps1 mouse model of Alzheimer's disease," Journal of Controlled Release, vol. 170, no. 1, pp. 111-119, 2013.

[47] G. Orive, R. M. Hernández, A. R. Gascón et al., "Cell encapsulation: promise and progress," Nature Medicine, vol. 9, no. 1, pp. 104-107, 2003.

[48] N. J. Abbott, "Blood-brain barrier structure and function and the challenges for CNS drug delivery," Journal of Inherited Metabolic Disease, vol. 36, no. 3, pp. 437-449, 2013.

[49] X. Tian, O. Brookes, and G. Battaglia, "Pericytes from mesenchymal stem cells as a model for the blood-brain barrier," Scientific Reports, vol. 7, no. 1, pp. 1-7, 2017.

[50] J. C. M. Schlachetzki, D. P. Pizzo, D. A. Morrissette, and J. Winkler, "Intracerebroventricular administration of nerve growth factor induces gliogenesis in sensory ganglia, dorsal root, and within the dorsal root entry zone," BioMed Research International, vol. 2014, Article ID 704259, 9 pages, 2014.

[51] P. D. Le Roux and S. Esquenazi, “Astrocytes mediate cerebral cortical neuronal axon and dendrite growth, in part, by release of fibroblast growth factor," Neurological Research, vol. 24, no. 1, pp. 81-92, 2002.

[52] H. Temsamani, S. Krisa, J.-M. Mérillon, and T. Richard, "Promising neuroprotective effects of oligostilbenes," Nutrition and Aging, vol. 3, no. 1, pp. 49-54, 2015.

[53] D. O'neil, "Peptides and their use," US 9169290B2, 2015.

[54] C. A. Lipinski et al., "Experimental and computational approaches to estimate solubility and permeability in drug discovery and development settings," Advanced Drug Delivery Reviews, vol. 23, no. 1-3, pp. 3-25, 1997.

[55] R. G. Duff, "Microencapsulation technology: a novel method for monoclonal antibody production," Trends in Biotechnology, vol. 3, no. 7, pp. 167-170, 1985.

[56] C. Spuch and C. Navarro, "Cell microencapsulation implants into the central nervous system," Recent Patents on Nanomedicinee, vol. 1, no. 1, pp. 60-67, 2011.

[57] M. M. Wen, N. S. El-Salamouni, W. M. El-Refaie et al., "Nanotechnology-based drug delivery systems for Alzheimer's disease management: technical, industrial, and clinical challenges," Journal of Controlled Release, vol. 245, pp. 95-107, 2017.

[58] M. Malhotra, C. Tomaro-Duchesneau, and S. Prakash, "Synthesis of TAT peptide-tagged PEGylated chitosan nanoparticles for siRNA delivery targeting neurodegenerative diseases," Biomaterials, vol. 34, no. 4, pp. 1270-1280, 2013.

[59] S. Naz, J. Beach, B. Heckert et al., "Cerium oxide nanoparticles: a "radical" approach to neurodegenerative disease treatment," Nanomedicine, vol. 12, no. 5, pp. 545-553, 2017.

[60] Y. Li, J. Fan, and D. Ju, "Neurotoxicity concern about the brain targeting delivery systems," in Brain Targeted Drug Delivery System, pp. 377-408, Elsevier, Amsterdam, Netherlands, 2019.

[61] L. Zhang, P. Zhao, C. Yue et al., "Sustained release of bioactive hydrogen by Pd hydride nanoparticles overcomes Alzheimer's disease," Biomaterials, vol. 197, pp. 393-404, 2019.

[62] S. G. Jeon, M.-Y. Cha, J.-I. Kim et al., "Vitamin D-binding protein-loaded PLGA nanoparticles suppress Alzheimer's disease-related pathology in 5XFAD mice," Nanomedicine: Nanotechnology, Biology and Medicine, vol. 17, pp. 297-307, 2019.
[63] X. Huo, Y. Zhang, X. Jin, Y. Li, and L. Zhang, "A novel synthesis of selenium nanoparticles encapsulated PLGA nanospheres with curcumin molecules for the inhibition of amyloid $\beta$ aggregation in Alzheimer's disease," Journal of Photochemistry and Photobiology B: Biology, vol. 190, pp. 98-102, 2019.

[64] K. A. Youssif, E. G. Haggag, A. M. Elshamy et al., "AntiAlzheimer potential, metabolomic profiling and molecular docking of green synthesized silver nanoparticles of Lampranthus coccineus and Malephora lutea aqueous extracts," PloS One, vol. 14, no. 11, 2019.

[65] D. Carradori, C. Balducci, F. Re et al., "Antibody-functionalized polymer nanoparticle leading to memory recovery in Alzheimer's disease-like transgenic mouse model," Nanomedicine: Nanotechnology, Biology and Medicine, vol. 14, no. 2, pp. 609-618, 2018.

[66] A. Vilella, D. Belletti, A. K. Sauer et al., "Reduced plaque size and inflammation in the APP23 mouse model for Alzheimer's disease after chronic application of polymeric nanoparticles for CNS targeted zinc delivery," Journal of Trace Elements in Medicine and Biology, vol. 49, pp. 210-221, 2018.

[67] X. Zheng, C. Zhang, Q. Guo et al., "Dual-functional nanoparticles for precise drug delivery to Alzheimer's disease lesions: targeting mechanisms, pharmacodynamics and safety," International Journal of Pharmaceutics, vol. 525, no. 1, pp. 237-248, 2017. 